\title{
Impact of sudden Arctic sea-ice loss on stratospheric polar ozone recovery
}

Article

Published Version

Scinocca, J.F., Reader, M.C., Plummer, D.A., Sigmond, M., Kushner, P.J., Shepherd, T.G. and Ravishankara, A.R. (2009) Impact of sudden Arctic sea-ice loss on stratospheric polar ozone recovery. Geophysical Research Letters, 36 (24). ISSN 0094-8276 doi: https://doi.org/10.1029/2009GL041239 Available at https://centaur.reading.ac.uk/32024/

It is advisable to refer to the publisher's version if you intend to cite from the work. See Guidance on citing.

Published version at: http://dx.doi.org/10.1029/2009GL041239

To link to this article DOI: http://dx.doi.org/10.1029/2009GL041239

Publisher: American Geophysical Union

All outputs in CentAUR are protected by Intellectual Property Rights law, including copyright law. Copyright and IPR is retained by the creators or other copyright holders. Terms and conditions for use of this material are defined in the End User Agreement.

\section{www.reading.ac.uk/centaur}

\section{CentAUR}

Central Archive at the University of Reading 
Reading's research outputs online 


\title{
Impact of sudden Arctic sea-ice loss on stratospheric polar ozone recovery
}

\author{
J. F. Scinocca, ${ }^{1}$ M. C. Reader, ${ }^{2}$ D. A. Plummer, ${ }^{1}$ M. Sigmond, ${ }^{3}$ P. J. Kushner, ${ }^{3}$ \\ T. G. Shepherd, ${ }^{3}$ and A. R. Ravishankara ${ }^{4}$ \\ Received 2 October 2009; revised 18 November 2009; accepted 25 November 2009; published 25 December 2009.
}

[1] We investigate the sensitivity of Northern Hemisphere polar ozone recovery to a scenario in which there is rapid loss of Arctic summer sea ice in the first half of the 21 st century. The issue is addressed by coupling a chemistry climate model to an ocean general circulation model and performing simulations of ozone recovery with, and without, an external perturbation designed to cause a rapid and complete loss of summertime Arctic sea ice. Under this extreme perturbation, the stratospheric response takes the form of a springtime polar cooling which is dynamical rather than radiative in origin, and is caused by reduced wave forcing from the troposphere. The response lags the onset of the sea-ice perturbation by about one decade and lasts for more than two decades, and is associated with an enhanced weakening of the North Atlantic meridional overturning circulation. The stratospheric dynamical response leads to a 10 DU reduction in polar column ozone, which is statistically robust. While this represents a modest loss, it has the potential to induce a delay of roughly one decade in Arctic ozone recovery estimates made in the 2006 Scientific Assessment of Ozone Depletion. Citation: Scinocca, J. F., M. C. Reader, D. A. Plummer, M. Sigmond, P. J. Kushner, T. G. Shepherd, and A. R. Ravishankara (2009), Impact of sudden Arctic sea-ice loss on stratospheric polar ozone recovery, Geophys. Res. Lett., 36, L24701, doi:10.1029/2009GL041239.

\section{Introduction}

[2] The effect of climate change on the expected recovery of stratospheric ozone is an important scientific and policyrelevant question [World Meteorological Organization $(W M O), 2007]$. To address this question adequately, especially in polar regions, requires the use of chemistry climate models (CCMs) encompassing the troposphere and stratosphere. The complexity and cost of these models has so far limited their application to a subset of the future scenarios regularly employed for the IPCC assessments and to simulations that do not include coupling to a global ocean model. For the 2006 Scientific Assessment of Ozone Depletion, the primary experiment designed to provide projections of

\footnotetext{
${ }^{1}$ Canadian Centre for Climate Modelling and Analysis, Environment Canada, Victoria, British Columbia, Canada.

${ }^{2}$ School of Earth and Ocean Sciences, University of Victoria, Victoria, British Columbia, Canada.

${ }^{3}$ Department of Physics, University of Toronto, Toronto, Ontario, Canada.

${ }^{4}$ Chemical Sciences Division, National Oceanic and Atmospheric Administration, Boulder, Colorado, USA.

Published in 2009 by the American Geophysical Union.
}

future ozone, known as "REF2" [Eyring et al., 2007], employed the moderate (A1B) IPCC AR4 future scenario for greenhouse gas concentrations and a future scenario (B2) for the evolution of ozone depleting substances that reflects controls resulting from the Montreal Protocol and subsequent amendments [ $W M O, 2003]$. Sea-surface temperatures (SSTs) and sea-ice distributions were specified from future projections made by coupled atmosphere-ocean models that participated in the IPCC AR4. The limitations of these sea-ice projections are becoming increasingly apparent as ground and satellite based observations continue to document dramatic losses of Arctic sea ice [e.g., Stroeve et al., 2007] that are not generally represented by the models. This raises questions about the reliability of future projections made with these modeled sea-ice distributions, such as those for Arctic stratospheric polar ozone [Eyring et al., 2007].

[3] Here we investigate the sensitivity of Northern Hemisphere $(\mathrm{NH})$ stratospheric polar ozone recovery to rapid Arctic sea-ice loss in the first half of the 21 st century, in one of the first applications of a chemistry climate model coupled to an ocean general circulation model. Two ensembles of three simulations are performed. The first is configured to simulate the REF2 experiment by Eyring et al. [2007]. The second ensemble, initialized from the first ensemble in 2025, also simulates the REF2 experiment but with a perturbation to the $\mathrm{NH}$ sea ice albedo designed to cause a rapid and complete loss of sea ice during Arctic summer. By comparing the two ensembles we are able to evaluate the potential impact of sudden Arctic sea-ice loss on $\mathrm{NH}$ polar ozone recovery.

\section{Model and Experiments}

[4] We employ the Canadian Middle Atmosphere Model (CMAM) [de Grandpré et al., 2000; Scinocca et al., 2008] to investigate this question. The CMAM is an atmospheric general circulation model that extends from the surface up to roughly $100 \mathrm{~km}$ and employs a standard set of chemical species and reactions describing stratospheric chemistry, including chlorine and bromine. Heterogeneous chemistry on polar stratospheric clouds (PSCs) includes a suite of 10 reactions on stratospheric ternary solution (PSC type $\mathrm{Ib}$ ) and ice particles (PSC-II). CMAM was a central contributor to the $W M O$ [2007] where it was identified with those models assessed to be in good agreement with observations [Eyring et al., 2006; Waugh and Eyring, 2008].

[5] CMAM is based on the Canadian Centre for Climate Modelling and Analysis third generation atmospheric general circulation model [Scinocca et al., 2008], which generally 


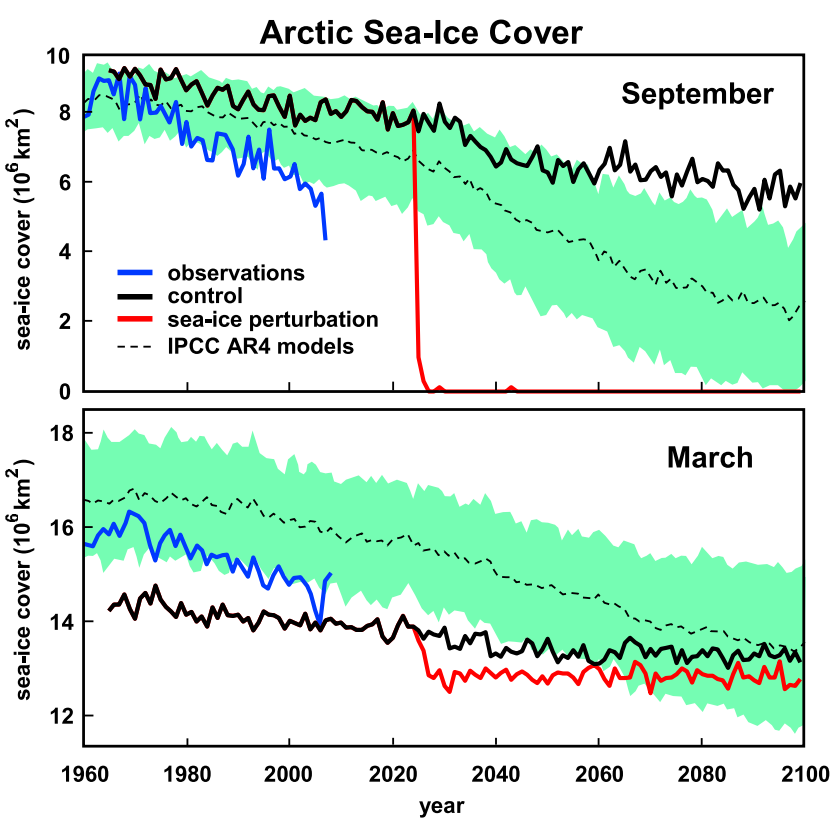

Figure 1. Time series of monthly averaged Arctic sea-ice extent at minimum (September) and maximum (March) from observations (thick blue line [Meier and Stroeve, 2008]), and the mean (dashed line) and standard deviation (green band) of 13 IPCC AR4 models (following Stroeve et al. [2007]). The average over the CMAM control ensemble and the CMAM sea-ice perturbed ensemble are shown respectively by the thick black and red lines.

operates coupled to a global ocean model. The ocean general circulation model used here is based on a modified version [Arora et al., 2009] of the National Center for Atmospheric Research community ocean model (NCOM1.3) [Gent et al., 1998]. The model employs a horizontal resolution of $1.86^{\circ}$ such that there are nine ocean grid boxes underlying each atmospheric grid box. There are 29 levels in the vertical and the vertical resolution increases toward the ocean surface, from $300 \mathrm{~m}$ in the deep ocean to $50 \mathrm{~m}$ in the top $200 \mathrm{~m}$.

[6] A coupled atmosphere-ocean initial state of CMAM was derived by performing a 100-year coupled atmosphereocean simulation under "pre-industrial" conditions. An ensemble of three realizations was then branched from the final state of this simulation; this ensemble ran under the REF2 scenario for 1950-2100. The realizations were identical apart from small perturbations to the atmospheric initial state. We call these three simulations the "control ensemble".

[7] To investigate the impact of rapid Arctic sea ice loss, an ensemble of three additional realizations with adjusted sea-ice optical properties was branched from the control ensemble at year 2025. The adjustment took the form of a reduction of sea-ice albedo in the $\mathrm{NH}$ to a value that was half that used for sea water. Such a perturbation is physically equivalent to darkening the sea ice continually with dust or soot, causing rapid melt. The adjustment to sea-ice albedo induces melt during the sunlit summer months while allowing ice to return naturally during the polar night of winter months. We call these three realizations the "perturbed ensemble".

\section{Results}

[8] Figure 1 shows time series over 1960-2100 of the ensemble-averaged, September and March averaged, sea-ice extent from the control ensemble (black lines) and perturbed ensemble (red lines). The sea-ice evolution of the control ensemble is similar to that of the IPCC AR4 models but with generally less Arctic sea ice at maximum (March). The adjustment of optical properties results in the complete elimination of September sea ice within the first few years and so presents one of the largest possible sea-ice-loss perturbations to the model.

[9] The largest response of the free atmosphere to the sudden loss of summertime sea-ice is found to occur in the NH springtime (March) polar stratosphere. Figure 2 (top) shows the time evolution of Arctic springtime column ozone. Over 1965-2007 the control ensemble is consistent with observations in terms of the magnitude of the year-toyear variability and the overall long-term decline. After 2000 the CMAM control ensemble displays a slow and continual increase of column ozone such that it eventually exceeds the levels that existed prior to halogen-induced ozone loss. This "super recovery" arises from the combined effects of the reduction of ozone-depleting substances and greenhouse gas induced changes of the stratospheric circulation [Shepherd, 2008] and is evident in essentially all of WMO's [2007] models [Eyring et al., 2007].

[10] Roughly one decade after the sea-ice perturbation is applied, the projected increase in ozone begins to slow. Between 2040 and 2060, the average column ozone over the pole differs between the two ensembles by $10 \mathrm{DU}$, significant at the 95\% confidence level (according to a standard t-test applied to the unsmoothed data). By 2080, the two ensembles are indistinguishable. Comparing these results with the inter-model differences of springtime column ozone projections presented by Eyring et al. [2007, Figure 7a] indicates that the impact of rapid sea-ice loss falls within current levels of modeling uncertainty. Nevertheless the response of Arctic springtime ozone to the rapid loss of sea ice in CMAM is statistically significant, and we consider its properties in the remainder of this section.

[11] Figure 2 also shows the zonal-mean Arctic springtime temperature and ozone response (perturbed minus control ensemble) averaged over 2040-2060. The sea-ice perturbation leads to a near-surface warming and a stratospheric cooling (Figure 2, bottom left), and to a negative ozone mixing ratio anomaly through the full polar stratosphere (Figure 2, bottom right). Partial column calculations of the ozone anomaly displayed in Figure 2 reveal that twothirds of the $10 \mathrm{DU}$ reduction in polar ozone comes from changes below $50 \mathrm{hPa}$. This stratospheric response is mainly due to dynamical changes. During 2040-2060, the perturbed ensemble undergoes an $8 \%$ reduction of February and March averaged $100 \mathrm{hPa}$ meridional heat flux from $40^{\circ}-80^{\circ} \mathrm{N}$ (significant at the $95 \%$ confidence level), which is proportional to the vertical component of the EliassenPalm (EP) flux entering the stratosphere. The EP flux at this altitude is primarily composed of planetary-scale Rossby waves, which drive the polar branch of the Brewer-Dobson 

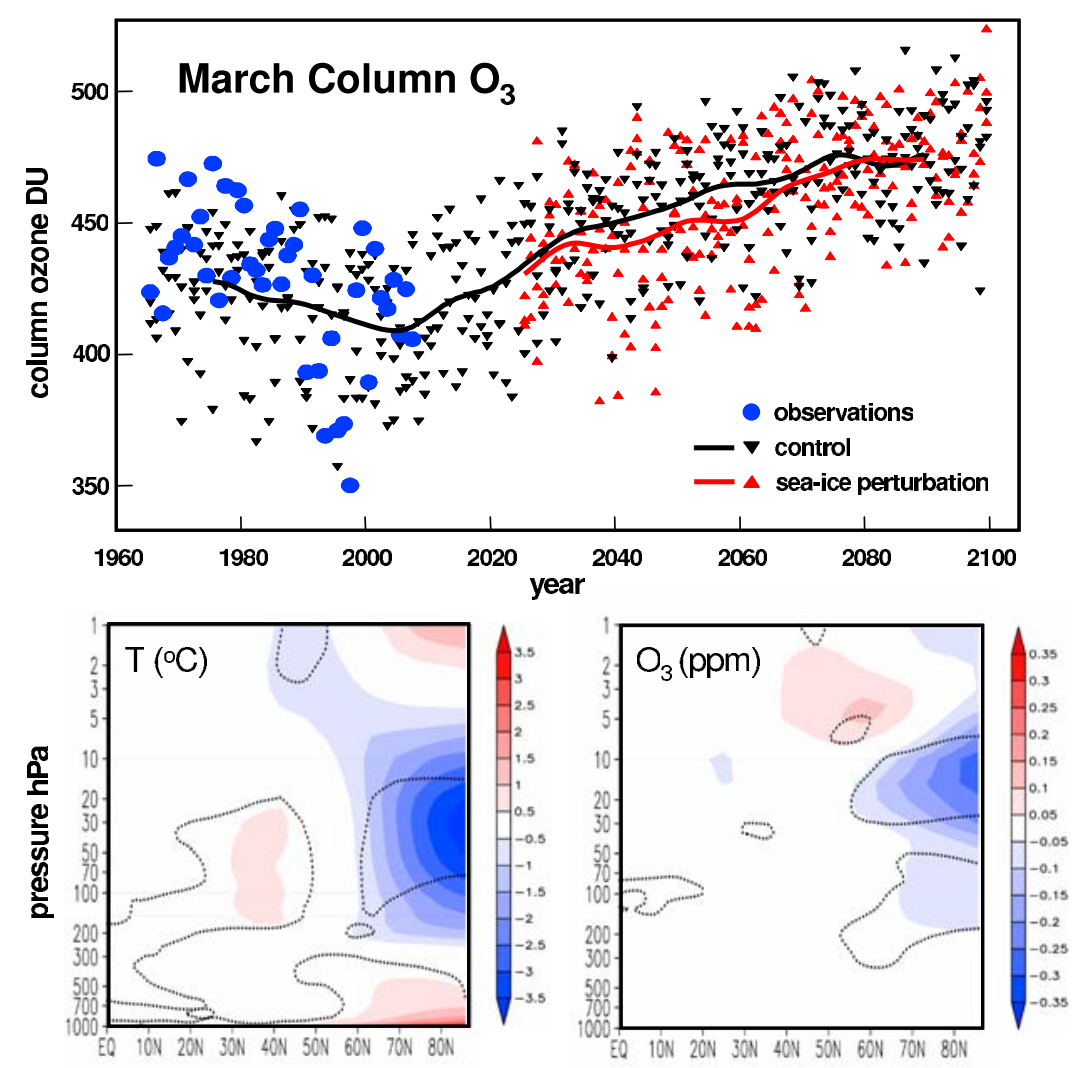

Figure 2. (top) Time series of Arctic springtime column ozone (averaged over $60^{\circ} \mathrm{N}-90^{\circ} \mathrm{N}$ and the month of March) from observations (updated from Fioletov et al. [2002], large blue dots), the CMAM control ensemble (black triangles and thick black line), and the average over the CMAM ensemble in which sea-ice was perturbed beginning in 2025 (red triangles and thick red line). Thick lines are derived from a running mean over the ensemble average employing a Gaussian window with a half-width of 10 years. Northern Hemisphere March anomaly (sea-ice perturbation minus control) of (bottom left) temperature and (bottom right) ozone mixing ratio averaged over 2040-2060, ensemble members, and longitude. Dotted contour lines indicate significance at the $95 \%$ confidence level.

circulation, transporting ozone downward into the polar lower stratosphere, and producing an adiabatic warming of this region. The planetary wave breaking associated with this EP flux also promotes mixing across the vortex edge. The weaker the EP flux, the weaker the transport and mixing of ozone into the vortex, and the colder the vortex [see, e.g., Shepherd, 2008].

[12] During 2040-2060 the downwelling over the pole $\left(60^{\circ} \mathrm{N}-90^{\circ} \mathrm{N}\right)$ in March is reduced by $8 \%$ in the perturbed ensemble. From the perspective of transport alone, this would lead to reduced values of polar ozone, as seen in Figure 2 (bottom right). In the presence of elevated concentrations of reactive halogen species, the low temperatures and isolated vortex promote chemical ozone loss. However during 2040-2060 the prescribed chlorine loading in these simulations has returned to rather low values and thus the chemical component of this ozone signal would be small relative to transport. (Note, however, that the increase in ozone near $5 \mathrm{hPa}$ and $55 \mathrm{~N}$ in Figure 2 (bottom right) is a chemical effect, associated with the lower temperature which slows the gas-phase ozone loss rates.)

[13] Circulation changes in the troposphere are the expected reason for the reduced planetary-wave forcing of the stratosphere in response to the sea-ice loss. Modeling and observational studies have linked below-normal sum- mertime Arctic sea-ice cover with planetary-scale circulation changes in the troposphere, including modified storm tracks and a reduced NH pole-to-equator temperature gradient, with the largest changes occurring in winter and spring [Singarayer et al., 2006; Seierstad and Bader, 2008; Francis et al., 2009]. The tropospheric circulation change in CMAM as illustrated by the March $500 \mathrm{hPa}$ geopotential height response is presented in Figure 3 for the two periods 20412060 and 2061-2100. During 2041-2060 a negativeNAM-like response is found during March, consistent with Seierstad and Bader [2008, see Figure 2b]. As in the stratosphere, a much weaker response is found during 2061-2100.

[14] While the sea-ice perturbation is nearly constant after 2025 (Figure 1), the response in both the stratosphere and troposphere is strong during 2040-2060 and weak before and after this period. This decadal scale variability of the atmospheric response suggests that the ocean may play a role in explaining the difference between the two ensembles. As a measure of the transient ocean response, Figure 3 (bottom) shows the evolution of the North Atlantic meridional overturning circulation (MOC) for the control and perturbed ensembles. The MOC response in the control ensemble falls within the range of other IPCC models undergoing an approximate 40\% decrease in strength over 


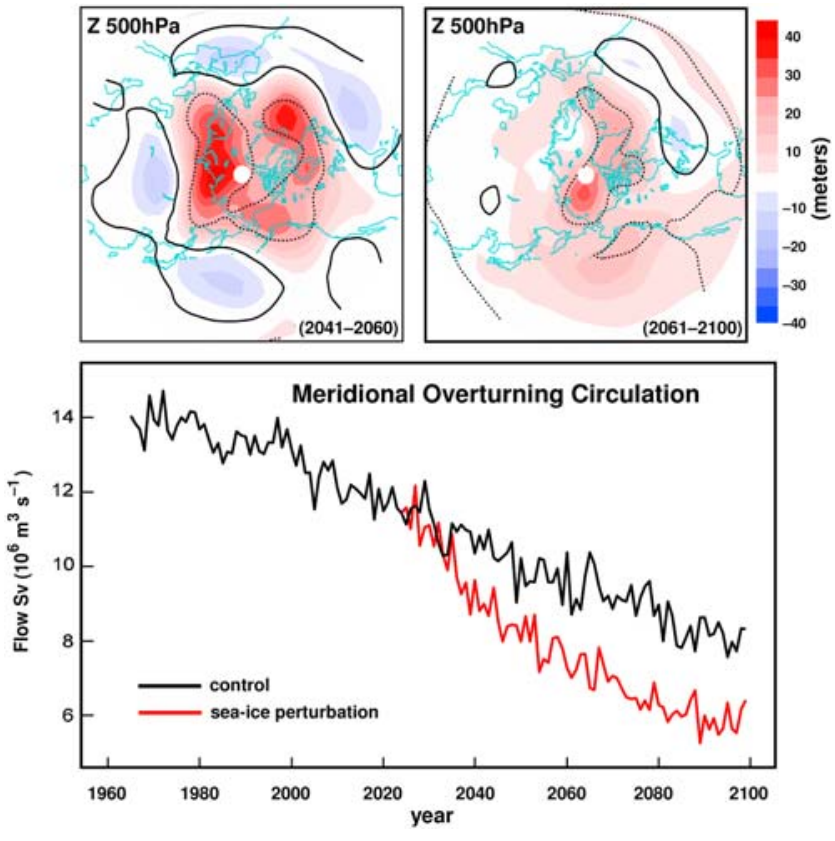

Figure 3. March average $500 \mathrm{hPa}$ geopotential height response between the control and perturbed ensemble for the two periods (top left) 2041-2060 and (top right) 20612100. The dotted line indicates the $95 \%$ significance level and the black solid line is the zero line. (bottom) Ensemble average time series of the North Atlantic meridional overturning circulation for the CMAM control (black line) and perturbed (red line) experiments.

the 21 st century. The influx of fresh water associated with the initial melt of sea ice in the perturbed ensemble contributes to a period of enhanced weakening of the MOC [cf. Bitz et al., 2007], which roughly coincides with the period of the significant atmospheric response. This does not provide a direct mechanism but suggests that an analysis of the ocean surface temperature and ocean-atmosphere energy transport might shed light on the transient atmospheric response.

\section{Summary and Discussion}

[15] We have considered the impact of rapid Arctic seaice loss on the recovery of Arctic ozone, within the context of the "REF2" climate-change/ozone-depletion-recovery scenario considered by the 2006 Scientific Assessment of Ozone Depletion $[W M O, 2007$, chap. 6]. Employing the Canadian Middle Atmosphere Model (CMAM) coupled to an ocean general circulation model, ensembles of "REF2" simulations were performed with, and without, a perturbation to sea-ice albedo designed to cause the complete elimination of summertime Arctic sea ice beginning in 2025. The primary stratospheric response is found to occur in NH springtime and is associated with Arctic cooling and a reduction of Arctic column ozone by about 10 DU for more than two decades after summertime sea-ice is lost. While this response is well within the current level of modelling uncertainty [Eyring et al., 2007], it represents a systematic perturbation that could potentially delay estimates of Arctic ozone recovery by roughly one decade.

[16] The stratospheric ozone and temperature response realized in the perturbed ensemble arises primarily from dynamical effects. In particular, there is less planetary-wave forcing of the stratosphere by the troposphere, resulting in a weaker high-latitude descent and therefore cooling over the pole together with a reduced downward flux of ozone into the polar lower stratosphere. This reduced ozone presumably feeds back to provide an additional radiative cooling, but the origin of the cooling is fundamentally dynamical. The tropospheric circulation response found here is similar in nature to that found in other studies of Arctic sea-ice loss. The temporal signature of both the stratospheric and tropospheric response implicates the role of the ocean in modulating the atmospheric response. The influx of fresh water associated with the initial melt of sea ice in the perturbed ensemble contributes to a period of enhanced weakening of the MOC, which roughly coincides with the period of the significant atmospheric response.

[17] The algorithm to determine photolysis rates of gasphase chemical reactions in CMAM assumes a constant surface albedo of 0.3 , and is thus insensitive to the perturbation to surface albedo that accompanies the loss of Arctic sea ice. However the near $10 \%$ reduction of sea-ice extent realized in March (Figure 1) would reduce the photolysis rates in the stratosphere by at most $10 \%$. This reduction would only slow gas phase photochemical ozone destruction, thus mitigating the impact of the primary dynamical response identified here and reducing its magnitude. Therefore, while the net impact on ozone would need to be investigated by a model with a more sophisticated treatment of photolysis rates, it is not expected to alter the primary conclusion that the springtime Arctic ozone response to seaice loss is small compared to current inter-model differences.

[18] However the sensitivity of photolysis rates to surface albedo suggests an additional summertime response to the loss of sea ice, which is absent in this study but which could be significant because of the dramatic change in sea-ice extent during the summer. As part of its seasonal cycle, from March to September, Arctic column ozone undergoes roughly a $30 \%$ reduction due to photochemically driven ozone loss [Fahey and Ravishankara, 1999]. The complete loss of summertime sea ice would correspond to a large albedo change in the Arctic and a slowing of the gas-phase photolysis rates, which on its own would suggest an increase in summertime ozone. However, the reduction in springtime polar ozone found here implies reduced summertime polar ozone [Fioletov and Shepherd, 2005], so the two effects act in opposite directions. Which one would dominate cannot be assessed by the present study and is left to future investigation.

[19] Acknowledgments. The authors thank Vitali Fioletov for providing an updated set of the observations presented in Figure 2 and John Fyfe for carefully reading the manuscript and providing helpful suggestions. This research has been supported by the Canadian Foundation for Climate and Atmospheric Sciences through the C-SPARC network.

\section{References}

Arora, V. K., G. J. Boer, J. R. Christian, C. L. Curry, K. L. Denman, K. Zahariev, G. M. Flato, J. F. Scinocca, W. J. Merryfield and W. G. Lee (2009), The effect of terrestrial photosynthesis down-regulation on the 20th century carbon budget simulated with the CCCma Earth System Model, J. Clim., 22(22), 6066-6088.

Bitz, C. M., J. C. H. Chiang, W. Cheng, and J. J. Barsugli (2007), Rates of thermohaline recovery from freshwater pulses in modern, Last Glacial Maximum, and greenhouse warming climates, Geophys. Res. Lett., 34, L07708, doi:10.1029/2006GL029237. 
Eyring, V., et al. (2006), Assessment of temperature, trace species, and ozone in chemistry-climate model simulations of the recent past, J. Geophys. Res., 111, D22308, doi:10.1029/2006JD007327.

Eyring, V., et al. (2007), Multimodel projections of stratospheric ozone in the 21 st century, J. Geophys. Res., 112, D16303, doi:10.1029/ 2006JD008332.

Fahey, D. W., and A. R. Ravishankara (1999), Summer in the stratosphere, Science, 285, 208-210.

Fioletov, V. E., and T. G. Shepherd (2005), Summertime total ozone variations over middle and polar latitudes, Geophys. Res. Lett., 32, L04807, doi:10.1029/2004GL022080.

Fioletov, V. E., G. E. Bodeker, A. J. Miller, R. D. McPeters, and R. Stolarski (2002), Global and zonal total ozone variations estimated from groundbased and satellite measurements: 1964-2000, J. Geophys. Res., 107(D22), 4647, doi:10.1029/2001JD001350.

Francis, J. A., W. Chan, D. J. Leathers, J. R. Miller, and D. E. Veron (2009), Winter Northern Hemisphere weather patterns remember summer Arctic sea-ice extent, Geophys. Res. Lett., 36, L07503, doi:10.1029/ 2009GL037274.

Gent, P. R., et al. (1998), The NCAR Climate System Model global ocean component, J. Clim., 11, 1287-1306.

de Grandpré, J., S. R. Beagley, V. I. Fomichev, E. Griffioen, J. C. McConnell, A. S. Medvedev, and T. G. Shepherd (2000), Ozone climatology using interactive chemistry: Results from the Canadian Middle Atmosphere Model, J. Geophys. Res., 105, 26,475-26,491.

Meier, W. N., and J. Stroeve (2008), Comparison of sea ice extent and ice edge location estimates from passive microwave and enhanced-resolution scatterometer data, Ann. Glaciol., 48, 65-70, doi:10.3189/ 172756408784700743.

Scinocca, J. F., N. A. McFarlane, M. Lazare, J. Li, and D. Plummer (2008), The CCCma third generation AGCM and its extension into the middle atmosphere, Atmos. Chem. Phys., 8, 7055-7074.
Seierstad, I. A., and J. Bader (2008), Impact of a projected future Arctic sea ice reduction on extratropical storminess and the NAO, Clim. Dyn., 33, 937-943, doi:10.1007/s00382-008-0463-x.

Shepherd, T. G. (2008), Dynamics, stratospheric ozone, and climate change, Atmos.-Ocean, 46, 117-138.

Singarayer, J. S., J. L. Bamber, and P. J. Valdes (2006), Twenty-first-century climate impacts from a declining Arctic sea ice cover, J. Clim., 19, 11091125 .

Stroeve, J., M. M. Holland, W. Meier, T. Scambos, and M. Serreze (2007), Arctic sea ice decline: Faster than forecast, Geophys. Res. Lett., 34, L09501, doi:10.1029/2007GL029703.

Waugh, D. W., and V. Eyring (2008), Quantitative performance metrics for stratospheric resolving chemistry-climate models, Atmos. Chem. Phys., 8, $5699-5713$.

World Meteorological Organization (WMO) (2003), Scientific assessment of ozone depletion: 2002, Global Ozone Res. Monit. Proj. 47, World Meteorol. Organ., Geneva, Switzerland.

World Meteorological Organization (WMO) (2007), Scientific assessment of ozone depletion: 2006, Global Ozone Res. Monit. Proj. 50, World Meteorol. Organ., Geneva, Switzerland.

P. J. Kushner, T. G. Shepherd, and M. Sigmond, Department of Physics, University of Toronto, 60 St. George St., Toronto, ON M5S 1A7, Canada.

D. A. Plummer and J. F. Scinocca, Canadian Centre for Climate Modelling and Analysis, Environment Canada, P.O. Box 3065 STN CSC, Victoria, BC V8W 2Y2, Canada. (john.scinocca@ec.gc.ca)

A. R. Ravishankara, Chemical Sciences Division, National Oceanic and Atmospheric Administration, 325 Broadway, Boulder, CO 80305, USA.

M. C. Reader, School of Earth and Ocean Sciences, University of Victoria, PO Box 3055, Victoria, BC V8W 3P6, Canada. 